\title{
VERBOS DE MOVIMIENTO EN RUSO Y ESPAÑOL: UNA VEZ MÁS SOBRE LA INTRANSITIVIDAD DIVIDIDA*
}

\author{
VOLHA BatSIUKOVA \\ Universidad Autónoma de Madrid \\ volha.batsiukova@uam.es
}

\begin{abstract}
Resumen
This paper investigates the relationship between the syntactic configuration of two classes of intransitive verbs of motion (the unaccusative and unergative verbs), on the one hand, and cerlain semantic properties of the respective predicates, encoded in the event structure and the semantic definition of the superficial subject, on the other hand. Hence, it is assumed that the unaccusativity is syntactically encoded and scmantically determined. It is shown that the semantic class of verbs of motion in not homogeneous and that its variable behavior with respect to different unaccusative diagnostics is due to the alternation of syntactically relevant aspects of meaning. The verbs of motion in Russian and Spanish are argued to fall into variuos subclasses, that arise from the combination of two sets of features: the delimitedness (wich can be semantically or syntactically induced) and animacy (which is especially important for the distribution of the scmantic component 'manner of motion').
\end{abstract}

\section{INTRODUCCIÓN**}

Desde que Perlmutter (1978) estableció en el marco de la Gramática Relacional la llamada Hipótesis Inacusativa, según la cual los verbos intransitivos se dividen en dos clases -los verbos inergativos (o intransitivos puros) y los inacusativos- no se paró de discutir sobre el papel que tiene la configuración sintáctica por un lado y el significado del verbo, por el otro, en el diagnóstico inacusativo. Aunque ya en los primeros tratamientos del fenómeno de la inacusatividad (Burzio, 1981, 1986; Halc y Kcyser, 1986; Belletti y Rizzi, 1987, etc.) se vieron reflejados los dos dominios: el sintáctico, por la posición que ocupa el único argumento de los verbos intransitivos, y el semántico, por la necesaria implicación de la noción de los papeles temáticos para poder relacionar el sujeto superficial de los verbos intransitivos con

* La realización de este trabajo ha sido parcialmente financiada por una bcca del Programa Nacional de Formación de Profcsorado Universitario (Ministerio de Educación, Cultura y Deporte) y por el proyecto de imvestigación «Las expresiones idiomáticas con verbos de movimiento. Propuesta de elaboración de un diccionario teórico, de uso y contrastivo» (Universidad Autónoma de Madrid).

Quiero expresar mi gratitud a Elena de Migucl, mi siempre atenta y generosa directora de tesis, quien contribuyó enormemente con sus comentarios y observaciones a que mejorara la versión inicial de este artículo.

** Algunos de los contevidos desarrollados a lo largo de este artículo (en concreto, la revisión bibliográfica y cuestiones relacionadas con las restricciones para la formación de construcciones de participio absoluto) han sido expuestos durante c1 XIX Encuentro de la Asociación de Jóvenes Lingüistas (Valencia, 2004). 
el sujeto o el objeto de los transitivos, jamás se llegó a aclarar con suficiente transparencia el mecanismo que establece la correspondencia entre ciertos papcles temáticos y determinadas posiciones. Como se deduce de una abundante bibliografia, tanto el enfoque estrictamente sintáctico (véase Rosen, 1984; Burzio, 1981, 1986, y otros) como el que propugna un estudio de la inacusatividad en términos exclusivamente semánticos (Van Valin, 1990; Zaenen, 1993, ctc.) fallan a la hora de explicar los llamados unaccusative mismatches, situaciones en las que los diferentes tests de inacusatividad se contradicen o hacen predicciones falsas. Así, desde el enfoque sintáctico resulta dificil o imposible explicar la existencia de los llamados verbos de comportamiento variable, que manifiestan características inacusativas en unos casos e inergativas en otros (en este grupo entran, entre otros, los verbos de movimiento); además, desde el punto de vista de la adquisición del lenguaje no está claro cómo puede distinguir el niño entre los dos tipos de intransitivos si una lengua (como el inglés o el español, por ejemplo) no posee marcadores morfológicos de la inacusatividad y si sc niega al mismo ticmpo que las pistas semánticas intervengan en dicho proceso. $\Lambda$ su vez, las teorías que rechazan la existencia de una configuración sintáctica común a todos los verbos inacusativos resultan incapaces de proporcionar un tratamiento unificado del fenómeno ya que tampoco parece habcr un único rasgo semántico que caracterice los verbos en cuestión y en consecuencia se limitan a constatar la compatibilidad o la incompatibilidad de los verbos con ciertas construcciones sintácticas. En cambio, la combinación de ambas visioncs, es decir, un enfoque que parte de la base de que la inacusatividad viene determinada por la semántica del verbo y aparece codificada en su sintaxis, consigue demostrar la existencia de una configuración sintáctica particular para cada tipo de los verbos intransitivos y cxplicar los casos de comportamiento variable destacando los rasgos semánticos sintácticamente relevantes (véase I evin y Rappaport Hovav, 1995, para un tratamiento sintáctico-semántico de la inacusatividad en inglés).

El objetivo de este trabajo es reflejar la heterogeneidad semántica del grupo de los verbos de movimiento en ruso y español (más allá de la clásica distinción entre los verbos de dirección inherente y los de manera de moverse) y demostrar que su comportamicnto respecto a las distintas pruebas de diagnóstico inacusativo se debe a la interacción de su estructura eventiva y las características semánticas de su sujeto superficial. Aunque, como se verá en el siguiente apartado, no faltan estudios que intentan relacionar los predicados inergativos e inacusativos con determinados tipos eventivos (o con ciertas subpartes de los eventos) asi como con determinados componentes semánticos del SN (véase, entre otros, Tenny, 1987; Grimshaw, 1992; Levin y Rappaport Hovav, 1995), sigue habiendo muchas cuestiones discutibles en torno a la repercusión de los dos tipos de información arriba mencionados en los resultados del diagnóstico inacusativo. Los principales interrogantes que puede suscitar dicho planteamiento y que me propongo resolver son:

1. ¿Existc una relación directa entre determinados tipos eventivos y la inacusatividad?

2. ¿Cómo de fiables son las pruebas de la inacusatividad de indole aspectual (construcciones de participio absoluto, construcciones con recién, estar al acabado de en español) y qué restricciones tienen?

3. ¿Cómo repercuten los rasgos semánticos del único argumento del verbo en su comportamiento sintáctico y cuáles de ellos son relevantes al respecto (la agentividad, el grado de afectación, la animacidad, etc.)? 
4. ¿Qué mecanismo se encarga de relacionar los rasgos semánticos del verbo y las características sintácticamente relevantes del SN?

5. ¿Constituye la inacusatividad una característica inherente de cada verbo o más bien se deriva composicionalmente?

Para abordar la tarea planteada contaré básicamente con el análisis composicional de la inacusatividad expuesto en Pustejovsky y Busa (1995a) y con la clasificación de los verbos de movimiento basada en el rasgo "causa externa directa» propuesta por Lcvin y Rappaport Hovav (1992).

A continuación revisaré brevemente algunos de los planteamientos que relacionan los rasgos aspectuales del predicado y algunos componentes semánticos de los $\mathrm{SN}$ quc lo constituyen con cl fcnómeno de la inacusatividad.

\section{EL ASPECTO Y LA INACUSATIVIDAD}

Tenny (1987) y Van Voorst (1986) han sido algunos de los autores que cuestionaron el papel temático del sujeto como criterio para distinguir entre inacusalivos e inergativos. Desde el punto de vista de estos autores, los predicados inacusativos pertenecen a ciertas clases aspectuales (estado o cambio de estado). Van Voorst lo hace basándose en el fenómeno de la pasiva impersonal (que llevó a Perlmutter a formular su hipótesis), y demuestra que dicha construcción se puede formar con un sujeto agente o no, dependiendo de si se trata de una realización u otro tipo de evento.

Grimshaw (1992) asume que una transición tiene una estructura compleja, y relaciona la segunda parte de una realización (estado o cambio de estado) con los predicados inacusativos, y la primera (actividad), con los inergativos. A diferencia de Tenny (1987) y Van Voorst (1986), Grimshaw sí tiene en cuenta la dimensión temática; para ella, la prominencia temática es paralela a la aspectual, de manera que el primer subevento siempre se asocia al papel temático más prominente, el de agente (este es el caso de los incrgativos); el segundo subevento que corresponde a los inacusativos está relacionado con un papel temático inferior en lit jerarquía, el de tema.

La postura de Ramchand (2002) es en cierto sentido próxima a la de Grimshaw (1992) en tanto que relaciona los subeventos con determinados componentes semánticos (que recuerdan mucho los papeles temáticos). Ramchand destaca tres subeventos: el subevento causativo, el proceso y el subevento resultativo, que se relacionan con los componentes semánticos de iniciador (initiator), experimentante (undergoer) y resultante (resultee) respectivamente. Según la clasificación que presenta la autora, un verbo inacusativo que participa en la alternancia causativa (como break, de $x$ broke), tendría especificados los subeventos de proceso y resultado en su representación formal; un verbo inacusativo que no necesariamente culmina en un estado resultante, como roll, tan sólo será constituido por el subevento-proceso; finalmente, los verbos inergativos de movimiento, como walk, contarían con el subevento causativo (asociado al iniciador) y el subevento-proceso (asociado al componente semántico de experimentante). En lo que se refiere a este último tipo de predicados, considero que la ventaja que tiene la representación de Ramchand (2002) consiste en que aparece reflejada la naturaleza ambigua del sujeto de los verbos de movimiento (en concreto, de los verbos de manera de moverse), que compagina su caractcristica semántica 
de agente, cuya voluntad provoca la acción, por un lado, con la de experimentante o tema, que 'sufre' el movimiento del verbo.

Entre las investigaciones que emplean el rasgo aspectual de la telicidad para diferenciar semánticamente las dos clases de verbos intransitivos se puede citar a Zaenen (1993) y Sanz (1996). Según Zaenen, el carácter télico o atélico de un evento repercute en la selección del auxiliar en holandés, y el rasgo controlable / no controlable influye en la formación de la pasiva impersonal. Además, Zacnen resalta una característica importantísima de la categoría del aspecto, que es su composicionalidad; es decir, el significado del verbo no es lo único que determina el aspecto de un predicado y una oración: los distintos clcmentos oracionales pueden modificarlo (un objeto dirccto delimitado, por ejemplo). La idea original de Sanz (1996) consiste en distinguir entre las lenguas con telicidad fuerte y telicidad débil. En una lengua con telicidad fuerte (el español, por ejemplo), un verbo télico debe tener un argumento interno sintáctico. En inglés, en cambio, sostiene que un argumento de un acusativo no se manifiesta como interno, por tanto, la telicidad es débil en esta lengua.

Antes de poner punto final a esta sección, creemos necesario mencionar que los enfoqucs basados en la estructura subeventiva más que en los tipos eventipos de Vendler y la noción de telicidad son los que más potencial explicativo tienen. En efecto, como señalan Cifuentes (1999: 52-53) y Mendikoetxea (1999), no existe relación dirccta cntrc los tipos de eventos por un lado y la intransitividad y sus subtipos, por el otro. Así, pese a que la mayoría de los verbos estativos se consideran como inacusativos (existir), algunos de ellos (como los verbos de emisión - brillar) ilustran la existencia de verbos estativos incrgativos; los verbos de movimiento no agentivos (rodar) son un ejemplo de actividades que corresponden a la clase de los inacusativos. La afirmación de que la telicidad está asociada a la inacusatividad tampoco parece cierta, puesto que hay verbos atélicos que se comportan como inacusativos: son los verbos de acabamiento gradual (enfriar, engordar) y los verbos de movimiento dirigido que no siempre tienen un punto final (caer o descender).

El objetivo del siguiente apartado será reflejar el contenido esencial de las dos teorías que constituyen el marco teórico del presente estudio.

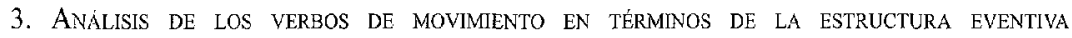

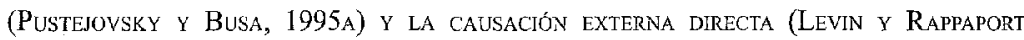
Hovav, 1992)

El tratamiento de la inacusatividad propuesto en Pustejovsky y Busa (1995a) se enmarca en la teoría del Lexicón Generativo, un sistema de representación léxico-semántico organizado en cuatro niveles de información ${ }^{1}$ :

1. Estructura argumental, que especifica el número y el tipo de argumentos lógicos;

2. Estructura eventiva, que define el tipo del evento (estado, proceso o transición ${ }^{2}$ ) cn función de su composición interna;

3. Estructura Qualia, que codifica la semántica de una unidad léxica y que está compuesta por los roles formal, constitutivo, télico y agentivo;

\footnotetext{
1 Véase Pustejovsky (1995h) para una presentación más amplia de la teoría del Lexicón Generativo.

2 Más en adelante presentarć una clasificación de eventos más compleja, desarrollada por Fernández Lagunilla y De Miguel (1999) y De Miguel y Fernández Lagunilla (2000) a partir de estos tres tipos eventivos.
} 
4. Estrucinra de Herencia Léxica, que explica cómo la estructura léxica está relacionada con otros tipos de estructura en el diccionario.

Como con razón apuntan los autores del estudio citado, la descripción del comportamiento de predicados inacusativos desde la perspectiva de clases fijas resulta ineficaz para captar la relación existente entre distintas formas del mismo predicado involucradas en la alternancia inacusativo-inergativa así como los casos en los que el efecto inacusativo surge de forma composicional. Pustejovsky y Busa consideran la inacusatividad como un caso de polisemia lógica, una posible realización de una entrada léxica infraespecificada que contempla varias interpretaciones de la misma unidad léxica dependicndo del contexto. Así, los ejemplos de $(1 \mathrm{a}, \mathrm{b})$ se obtienen a partir de la misma entrada léxica infraespecificada (lc) mediante la focalización de diferentes componentes de la estructura eventiva y los roles de qualia que les corresponden:

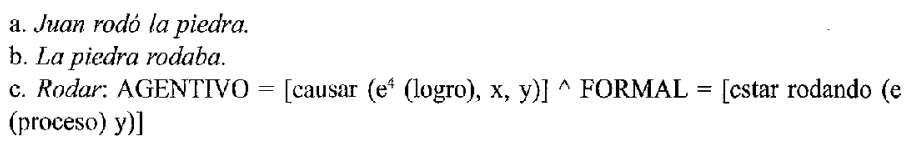

Micntras en el ejemplo (1a) se focaliza el subevento causativo de rodar ("hacer rodar', un logro), en (lb) el componente prominente es el evento causado. Dado que en éste último caso es subevento causativo se encuentra «oscurecido» de alguna manera, el evento de rodar se contempla como espontáneo, ocurrido sin la intervención de un agente y, por tanto, inacusativo. El subevento causativo y el estado o proceso resultante están asociados, a su vez, a los roles agentivo y formal, que codifican el origen del evento y sus rasgos más característicos (la manera de moverse en cl caso de los verbos de movimiento) respectivamente. Éste es, en rasgos generales, el mecanismo que relaciona el sujeto superficial de un verbo usado como inacusativo con la posición de objeto en la sintaxis: si el evento causativo y el argumento agente (sujeto sintáctico) ligado con ćl no se expresan y, en cambio, se focaliza el evento resultante y el argumento objeto, la interpretación del predicado será inacusativa.

Para los verbos inacusativos que no tienen una variante causativa, Pustejovsky y Busa proponen una estructura conceptual parecida, la única diferencia es que la focalización de subeventos para estos verbos está predeterminada léxicamente, de manera que el componente prominente siempre va a ser el resultante. Éste sería el caso de los verbos de dirección inherente:

3 Los dos roles que más importancia tienen para este trabajo son el agentivo y el formal. El rol agentivo codifica los factores implicados en el origen o la creación del objeto (que son el creador, el artefacto, la clase natural y la cadena causal cuyo resultado es la existencia del objeto) y el formal expresa los rasgos distintivos del objeto (su orientación espacial, cl tamaño, la forma, la dimensionalidad, el color y la posición). Asi, por ejemplo, el sustantivo novela estaría definido como 'escribir' por el rol agentivo y como 'libro' por el rol formal.

$4 \quad e$ es una variable de evento. 
liegar: AGENTIVO $=[\text { moverse }(\mathrm{e} \text { (proceso), } \mathrm{x})]^{\wedge}$ FORMAL $-\mathrm{y}$ : ubicación $[\mathrm{a}$ $\left(\mathrm{e}^{* 5}(\right.$ estado $\left.\left.), \mathrm{x}, \mathrm{y}\right)\right]$

Otro fenómeno de sobra conocido que se trata en el estudio en cuestión es el comportamiento variable de los verbos de manera de moverse, que se caracterizan como inacusativos o inergativos dependiendo de si van acompañados o no de un adjunto de final de movimiento. Como estos verbos sólo cuentan con un participante y, en principio, con un solo subevento - proceso atélico, el tratamiento arriba esbozado no se puede aplicar en este caso. Los autores proponen que cl responsable de esta alternancia es el proceso de co-composición, que se acliva cuando interaccionan determinados rasgos de los componentes del predicado y altera las propiedades inherentes de este. Así, un SP de destino que se combina con un verbo de manera de moverse dota éste de un estado resultante del que los verbos de manera de moverse carecen cuando se toman por separado. A diferencia de lo que ocurre con los verbos de dirección inherente, éste es un ejemplo de focalización sintáctica, y no léxica. En (3) representamos el resultado de la co-composición del verbo de manera de moverse correr con el adjunto de final de movimiento a casa:

$$
\begin{aligned}
& \text { correr a casa: } \left.\left[\text { correr: FORMAL }=[\text { moverse }(\mathrm{e} \text { (proceso) }) \mathrm{x})^{\wedge} \text { rápido }(\mathrm{e} \text { (proceso })\right)\right]<{ }_{\alpha}{ }^{6} \\
& {[a(\mathrm{e} \text { (estado) } \mathrm{x}, \text { casa) }]}
\end{aligned}
$$

Por último, merece la pena mencionar una distinción que establecen Pustejovsky y Busa respecto a la codificación del rasgo «manera de moverse» para los distintos verbos del grupo en cuestión. Basándose en los datos del italiano, y en particular en la (in)compatibilidad de determinados verbos de manera de moverse con SP adjuntos, los autores proponen que la manera de moverse puede caracterizar el evento o su participante. Si la manera de moverse está asociada al evento ( $y$ constituye su rasgo distintivo representado por el rol formal), el verbo es compatible con los SP con a (4a), y si este componente semántico refleja la manera individual del participante (y se adscribe, por tanto, al rol agentivo), la construcción con $a$ será rechazada por el verbo $(4 \mathrm{~b})$ :
a. Giovanni è corso a casa. / Juan corrió a casa.
correre: FORMAL $=[\text { moverse (e (proceso), } \mathrm{x})^{\wedge}$ rápido (e (proceso))]
b. *Giovanni è camminato al negozio. / ?? Juan caminó a la tienda.
camminare: Agentivo $=\left[\right.$ mover $\left(\mathrm{e}^{\prime} \text { (proceso), } \mathrm{x}, \mathrm{y} \text { : piernas) }\right]^{\wedge}$ Formal $=$ [moverse $\left(\mathrm{e}^{2}\right.$ (proceso, $\left.\left.\mathrm{x}\right)\right]$

Teniendo en cuenta que tipológicamente las lenguas romances no pueden fusionar en la misma forma verbal los componentes semánticos de manera y desplazamiento (a difcrencia del resto de las lenguas indoeuropeas y el chino) ${ }^{7}$, el comportamiento de los verbos de movimiento italianos no es asombroso: sencillamente el italiano conceptualiza el verbo correr como un verbo de desplazamiento, y caminar como un verbo de manera de moverse.

EI asterisco marca el subevento focalizado.

El signo $<$ marca la precedencia temporal del subevento al que sigue.

Talnyy (1985) fue quien describió los mencionados modelos de lexicalización. 
Como ya se ha adelantado en la introducción, lo novedoso del análisis semántico de los verbos de movimiento expuesto en Levin y Rappaport Hovav (1992) consiste en que las autoras proponen que el grupo de los verbos de manera de moverse se subdivida en dos, en función del rasgo «causa externa directa» (CED) que, como se verá a continuación, repercutc de forma decisiva (junto con los componentes semánticos «dirección» y «manera») en la configuración sintáctica del verbo, que puede ser inacusativa o inergativa. Reproducimos en (5) la clasificación de los verbos de movimiento que resulta de la combinación de los tres rasgos mencionados (Levin y Rappaport Hovav, 1992:253);
a. verbos del tipo arrive "llegar":
DIRECCIÓN
b. verbos del tipo run 'correr':
MANERA, -CED
c. verbos del lipo roll 'rodar':
MANERA, +CED

El comportamiento sintáctico de cada uno de estos grupos de define en dos reglas que se citan en (6) (Levin y Rappaport Hovav, 1992:253, 254). La primera se aplica a los verbos de dirección inherente, y la segunda a los de manera de moverse:

(6) Regla 1: Los verbos que tienen especificada en su contenido scmántico la dirección inherente tienen una configuración sintáctica inacusativa.

Regla 2: Si el significado del verbo implica la existencia de una causa externa directa, el verbo tiene una configuración sintáctica inacusativa; en caso contrario la configuración sintáctica del verbo es inergativa.

Nótese que la regla 2 da cuenta del comportamiento sintáctico de verbos como rodar (en su acepción intransitiva), que desde la perspectiva de los tipos eventivos se consideraría como inergativo, puesto que no es un estado ni una transición sino un proceso. No obstante, como es un proceso de causa externa, sí puede ser clasificado como inacusativo scgún la regla 2 .

De una manera similar a la de Pustejovsky y Busa (1995a), Levin y Rappaport Hovav (1992) apuntan quc un verbo de manera de moverse como correr (7a), a pesar de no contar a priori con el rasgo de dirección inherente (como el verbo llegar y otros), puede adquirirlo una vez combinado con un complemento de destino (7b):

$$
\begin{aligned}
& \text { a. correr (manera de moverse): [x MOVERSE corricndo (manera)] } \\
& \text { b. correr (direccional): [x IR A y MEDIANTE [x MOVERSE corriendo (manera)] }
\end{aligned}
$$

Tanto Pustejovsky y Busa como Levin y Rappaport Hovav intentan equiparar el comportamiento inacusativo de los verbos de dirección inherente al de los de manera de moverse con un SP sea interpretando los dos casos como ejemplos de focalización de subeventos (léxica para los verbos de dirección inherente y sintáctica para los de manera de movcrse con un SP de destino), sea dotando los verbos de manera de moverse del rasgo de dirección (IR A).

Las posturas defendidas en los dos estudios también son compatibles en cuanto a la subdivisión de los verbos de manera de moverse, ya que la noción de «causa externa directa» se puede derivar de la Estructura Qualia de dichos verbos y sus SN: para los verbos de causa externa (como rodar en su variante inacusativa, en (1)), el rasgo 'manera de moverse' 
Verbos de movimiento

\begin{tabular}{|c|c|}
\hline Verbos de direccion inherente & Verbos de manera de moverse \\
\hline Inacusativos & Agentivos \\
\hline \multirow{4}{*}{$\begin{array}{l}\text {-aceptan la CPA los que expresan punto } \\
\text { final } \\
\text { Aterrizado el avión, los pasajeros salieron en } \\
\text { estampida. } \\
\text {-En italiano van con essere } \\
\text { Sono salito sulla montagna. ('Subí a la } \\
\text { montaña') } \\
\text {-Denotan cambio de ubicación, igual que } \\
\text { sentar(se), levantar(se), ete. La diferencia es } \\
\text { que éstos tienen variantes transitivas que } \\
\text { denotan eventualidades de causa cxterna. }\end{array}$} & $\begin{array}{l}\text { 1. Inergativos (en italiano seleccionan avere) } \\
\text { Juan corrió para salvar su vida. (Juan-agente) }\end{array}$ \\
\hline & $\begin{array}{l}\text { 2. Inacusativos con un adjunto de final de } \\
\text { movimiento } \\
\text { Juan corrió a casa.(Juan-tema afectado, entidad } \\
\text { que sufre cambio de lugar) }\end{array}$ \\
\hline & No agentivos \\
\hline & $\begin{array}{l}\text { Inacusativos } \\
\text { Su significado apoyaría la hipótesis de que son } \\
\text { inacusativos } \\
\text { Botar, rodar, girar }\end{array}$ \\
\hline
\end{tabular}

Esquema 1

Es significativo un apunte que se hace en Mendikoetxea (1999) sobre los verbos intransitivos de movimiento: al igual que en el caso de los verbos de emisión percibida sensorialmente, la clasificación de los verbos de movimiento «se ha de hacer atendiendo sobre todo a razones de significado, al carecer de diagnósticos de carácter morfosintáctico» (Mcndikoctxca, 1999: 1605). Sin embargo, como se puede observar en el csquema 1, la misma autora recurre al diagnóstico morfosintáctico del auxiliar en italiano para justificar la interpretación de Juan corrió para salvar su vida como inergativo, y Juan corrió a casa como inacusativo (un método un tanto disculible teniendo en cuenta que el fenómeno de la inacusatividad no tiene por qué manifestarse de la misma manera en dos lenguas distintas).

Lo que se expone a continuación es una propuesta de clasificación de los verbos de movimiento en español en función de su estructura eventiva y determinados rasgos semánticos codificados a nivel de qualia (en cspecial por $\mathrm{cl}$ rol formal y cl agentivo). La validez de dicha propuesta se comprobará mediante distintas pruebas de inacusatividad: oraciones con SN pospuestos sin determinante, construcciones con acabado de, estar al y las construcciones de participio absoluto (CPA) ${ }^{8}$. Si bien el español carece de manifestaciones sintácticas claras de la inacusatividad que sí están presentes en otras lenguas romances (el francés y el italiano) - me refiero a la selección de un auxiliar distinto para los verbos inacusalivos y los inergativos (it. essere y avere frente a fr. être y avoir), la concordancia del participio con el sujeto en las formas verbales compuestas con essere y être y la cxistencia do un clítico partitivo (fr. en, it. ne) para los objetos de los transitivos

8 Véase Cifuentes (1999) para una visión crítica de la validez de estas pruebas. 
y los sujetos de los inacusativos ${ }^{9}$ - los fenómenos sintácticos del castcllano arriba citados, aplicados en su conjunto, nos pueden ayudar a discriminar los verbos inacusativos.

Así pucs, destacamos los siguientes tres grupos dentro de la clase de los verbos de movimiento:

1. Verbos de dirección inherente ${ }^{10}$ : acercarse, acudir, adelantarse, alejarse, aproximarse, arribar, ascender, asomarse, atrasar, avanzar, bajar, caer, descender, desplazarse, dirigirse, elevarse, encuminarse, entrar, irse, llegar, moverse, partir, regresar, salir, subir, venir, volver.

Los verbos de este grupo son inherentemente télicos, ya que están delimitados por la determinación de su trayectoria ${ }^{11}$. En términos de Pustejovsky y Busa (1995a), los verbos en cuestión tienen focalizado el subevento resultante (léxicamente en el caso de acudir, entrar, venir, etc. y de manera sintáctica si cl verbo tiene un correlato causativo: asomarse, elevarse, encaminarse, y otros) y carecen, por tanto, de la fase causativa o no la visualizan. $\mathrm{Su}$ interpretación como inacusativos se deduce del hecho de que el estado resultante que ellos denotan está relacionado con el argumento objeto, el único SN que se proyecta puesto que al no existir el subevento causativo tampoco hay un argumento sujeto.

En el caso de SN inanimado el sujeto superficial se interpreta como tema (Llegó la carta), y en el de un SN animado, como causante del cvento (agente) y experimentante del mismo a la vez (Llegó Juan). Consideramos que es muy importante asumir desde el principio que el SN animado de los verbos de movimiento puede ser ambiguo en cuanto a su interpretación en términos de papeles temáticos: en determinados contextos se puede interpretar como agente por ser quien provoca la acción por una parte, y en otros como tema o experimentantc porque el esfuerzo que hace se aplica a su propio cuerpo haciendo que cambie de posición.

Así proponemos una solución que pretende conciliar dos puntos de vista opuestos en cuanto al papel temático del SN cn construcciones inacusativas con los verbos de movimiento: uno, defendido por quienes establecen una relación directa entre la posición de objeto y el papel de tema y asumen, por tanto, que el sujeto superficial en estos casos siempre es el tema, y otro que se atañe a consideraciones de carácter semántico y relaciona el SN con el papel de agente. Uno de los estudiosos que defienden que los verbos de movimiento en español son agentivos y, por tanto, no son inacusativos, es Cifuentes (1999). También Gràcia (1989) ha señalado que las pruebas para demostrar que un sujcto cs agente funcionan con los inacusativos de movimiento: estos verbos admiten el imperativo $(9 \mathrm{a}, \mathrm{b})$, la subordinación a verbos del tipo ordenar o prometer $(9 \mathrm{c})$, la modificación mediante adverbios de voluntad (9d) y aparición en subordinadas finales (9e) (cito los ejemplos por Cifuentes, 1999: 27):

9 Diacrónicamente este tipo de fenómenos si esiuvieron presentes en el castellano, pero terminaron por desaparecer. En el estudio de Castillo (2002) se aportan prucbas de que la distribución de auxiliares en el castellano clásico cra básicamente la misma que se manifiesta hoy en dia en italiano, a saber, ser se usaba como auxiliar de los verbos de movimiento asi como de los inacusativos, impersonales y reflexivos, mientras que haber acompañaba los verbos transitivos.

10 Utilizaremos los verbos de dirccción inherente más usados enumerados en De Miguel (I992).

11 Aunque algunos de ellos son ambiguos en este sentido en tanto que no sólo se puede focalizar en determinados contextos el objetivo final del movimiento sino también la trayectoria: hajar, elevarse, descender, volver, ctc. Es un matiz importante que retomaremos a la hora de hablar de las restricciones en la formación de las CPA. 
(9)
a. Vete de aquí.
b. Ven a mi lado.
c. Le ordenó que llegara pronto.
d. Llegó tarde deliberadamente.
e. Entró en el despacho para preguntarle dudas.

Probemos ahora, mediante los diagnósticos de inacusatividad, que los verbos de dirección inherente son inacusativos en español.

Todos los verbos enumerados supra se pueden utilizar en oraciones con SN pospuesto sin determinante que, como se sabe, se forman con los verbos transitivos e inacusativos, pero resultan agramaticales con los inergativos (De Miguel, 1992: 47). Citamos en (10) algunos ejemplos:

(10) a. Si, en el Trópico todo llega tarde[...], más de cuando en cuando arriban visitaciones que refrescan ta densidad del clima y la limpidez de las ferias. (CREA)

b. Hoy se desplazan investigadores a varias zonas del pais. (CREA)

c. Sólo entran personas. (CRE $\Lambda$ )

d. Cuando se acercan elecciones las promesas de este Gobierno siempre son muchas [...]. (CREA)

En lo que se refiere a las construcciones con acabado de, estar al y las CPA, aunque éstas cuentan con una serie de restricciones que se explicarán en el siguiente apartado, la mayoría de los verbos de dirección inherente sí las aceptan, como se deduce de los ejemplos:

(11) a. Llamaba mi papá, acabado de llegar a Barranquilla sin anunciarse [...]. (CREA) b. La observación aparece en un estudio acabado de salir de la SRI International [...]. (CREA)

c. ¿Sabias que se producen más accidentes cuando la nieve está mejor y acabada de caer? (Google)

(12) a. El telón final podria estar al caer en el teatro Marti. (CREA)

b. Mi hijo va a estar al llegar... (CREA)

c. Pero Martinez l...। dijo: «Tu marido está al venir». (CREA)

d. - Pero debe de estar al volver -me dijo [...]. (CREA)

(13) a. Vuelto Enrique a casa, en seguida nos dirigimos a la comisaria.

b. Llegado el presidente empezó la reunión.

c. Bajado Pepe de la montaña, lo primero que hizo fue ir al hospital.

2. Verbos de manera de moverse que tienen el rasgo 'manera de moverse' asociado al rol agentivo (verbos de causa interna): andar; arrastrarse, caminar, correr, gatear, nadar, pasear, renquear, volar, etc. ${ }^{12}$.

12 Son algunos de los verbos de manera de moverse tratados en Morimoto (2001: 43), al igual que los verbos del terecr grupo. 
Son eventos de estructura simple: procesos inherentemente atélicos e inergativos. Sin embargo, el efecto inacusativo se puede conseguir mediante el proceso de co-composición (véase el §3) con un SP, convirtiendo el proceso en una transición télica y un evento dotado de dirección.

Como era de esperar tralándose de unos verbos inergativos, los representantes de este grupo no son compatibles con los SN pospuestos sin determinante (14), y lampoco con las construcciones con acabado de (15), estar al (16) y las CPA (17):

(14) a. *Nadaron americanos.

b. *Corren cucarachas.

(15) a. *Joven acabado de nadar.

b. *Acabado de caminar, se fue a casa.

(16) a. *Debe de estar al pasear:

b. *No creo que tu hermano esté al volar.

(17) a. *Volado Juan, nos sobrevino la tristeza.

b. \# Arrastrado el mendigo hasta el mercadillo, se puso a pedir limosnat ${ }^{13}$.

3. Verbos de manera de moverse que tienen el rasgo 'manera de moverse' asociado al rol formal (verbos de causa externa): deslizarse, rodar, girar, flotar, volar' ${ }^{14}$, etc.

Todos los verbos enumerados (excepto flotar ${ }^{15}$ ) tienen un correlato causativo (Juan deslizó la mano - La mano se deslizó) y en consecuencia representan el subevento resultante focalizado de una transición básicamente causativa. Concluimos, pues, que los verbos de este grupo son inacusativos, independientemente de si son télicos o no (distinción que sí cs importante para el segundo grupo que sólo muestra comportamiento inacusativo en presencia de un SP de destino).

Siendo inacusativos, los verbos del tercer grupo (incluida la variante inacusativa de volar) pueden formar oraciones con un $\mathrm{SN}$ pospuesto sin determinante:

(18) a. Pero los planetas no son los únicos habitantes del sistema solar: a su alrededor giran lunas, se desplazan asteroides, vuelan cometas... (Google) plásticos, trapos, trozos de tela... (CREA)

c. En el mes de la Patria, ruedan cabezas y se pierden frenos. (Google)

13 La única lectura posible de esta oración es la pasiva. Una CPA se interpreta como pasiva cuando la base verbal es transitiva (porque supone la existencia de dos argumentos) y como activa cuando cl verbo cs inacusativo (en este caso sólo hay un argumento).

14 Nótese que volar, como inergativo, también estaba incluido en el segundo grupo. Como se poirá comprobar en seguida, la diferencia de significado de las dos acepciones del mismo verbo repercute en su configuración sintáctica: volar del tercer grupo es inacusativo.

15 Flotar es singular en tanto que es un estado que carece de subevento causativo: no depende de la intervención de ningún agente ni necesila ninguna otra fuerza exterior para poder darse. Como para el resto de los verbos do este grupo, el rasgo 'manera de moversc', adcmás de caracterizar el evento, representa también una cualidad del SN, que tiene que reunir ciertos rasgos en su rol formal ('ser capaz de flotar', por ejemplo), para poder acompañar al verbo. En esto flotar se diferencia de su equivalente ruso, plyt', que puede tener asociado el rasgo'mancra dc moverse' tanto al rol agentivo (y proycetarse en consecuencia como in evento de causa interna, 'nadar') como al formal ( $y$ denotar un evento de causa externa, 'flotar'). 
El hecho de los verbos en cuestión no pueden participar en construcciones con acabado de, estar al y las CPA (véase los ejemplos de (19)), y que en principio podría refutar nuestra afirmación sobre su naturaleza inacusativa, se explica por razones que no tienen que ver con la inacusatividad, puesto que éste es un requisito imprescindible, pero no único para la correcta formación de las construcciones mencionadas.

(19) a. *Un pedrusco acabado de rodar dio contra el muro.

b. *El sol estará al girar.

c. *Flatadas las velas, empezó la fiesta.

Antes de pasar a examinar en el siguiente subapartado las restricciones sobre la formación de las construcciones que inciden en las características aspectuales de los verbos -las CPA y las construcciones con acabado de y estar al- proponemos en (20) una tabla que resume la clasificación de los verbos de manera de moverse en español en función de su estructura eventiva (representada de manera general por los rasgos télico y atélico) y su Estructura Qualia (que distingue entre los verbos que tienen asociado el rasgo 'manera de moverse' al rol agentivo o al formal):

(20)

\begin{tabular}{|l|l|l|}
\hline & $\begin{array}{l}\text { Manera moverse - rol agentivo } \\
\text { (causa interna) }\end{array}$ & $\begin{array}{l}\text { Manera moverse - rol formal } \\
\text { (causa externa) }\end{array}$ \\
\hline$\underline{\text { Télico }}$ & $\begin{array}{l}\text { Inacusativo } \\
\text { Juan corrió a su casa. }\end{array}$ & $\begin{array}{l}\text { Inacusativo } \\
\text { La piedra rodó hasta el pozo. }\end{array}$ \\
\hline \multirow{2}{*}{ Atélico } & Inergativo & $\begin{array}{l}\text { Inacusativo } \\
\text { La piedra rueda. }\end{array}$ \\
\hline
\end{tabular}

\subsection{Restricciones sobre la formación de las CPA, las construcciones con acabado de y estar al}

Como se ha visto en la sección anterior, no todos los verbos inacusativos pueden formar parte de las construcciones con 'acabado de' y CPA. De Miguel (1992) explica que no basta con que un verbo sea inacusativo para que sea compatible con la CPA, además, tiene que ser perfectivo. Por esto el ejemplo $(19 \mathrm{c})$ (*Flotadas las velas, empezó la fiesta.) es agramatical. Efectivamente, como hemos señalado, los verbos de manera de moverse son inherentemente atélicos.

Sin embargo, también algunos de los verbos de dirección inherente, que suelen ser eventos delimitados, rechazan la CPA.

Para explicar la causa de la (in)compatibilidad de ciertos verbos de dirección inherente con la CPA nos basaremos en la tabla de los verbos de movimiento y dirección (De Miguel, 1992: 78) ${ }^{16}$ que recoge los verbos que pueden participar en la CPA (alejarse, arri-

16 Excluimos de la lista los verbos de manera de moverse deslizarse, escurrirse, rodar y resbalar por las razones expuestas supra. 
har, ascender, asomarse, bajar, caer, descender, desplazarse, elevarse, encaminarse, entrar, llegar, partir, salir, subir, venir) y los que no tienen esta posibilidad (acercarse, acudir, adelantar(se), aproximarse, atrasar, avanzar, dirigirse, irse, moverse, regresar, volver ${ }^{17}$ ). Como acabamos de mencionar, la prueba de la CPA tiene una restricción (De Miguel, 1992: 74) ${ }^{18}$ : dado que el participio en la construcción absoluta es aspectualmente perfectivo ${ }^{19}$, ello implica que el verbo sobre el que se forma debe denotar un evento que, para realizarse, ha de alcanzar su estado final (es decir, ha de tener un término o un resultado). Este planteamiento explicaría cl hecho de que rechace la CPA el verbo estativo atrasar ${ }^{20}$.

Relacionando el requisito de perfectividad con las clases eventivas, podriamos deducir que los eventos perfectivos (los logros y las realizaciones) admiten la CPA, y los no perfectivos (procesos y cstados) la rechazan (como los verbos de manera de moverse que, en principio, pueden ser inacusativos si no son agentivos - el grupo 3).

No obstante, entre los verbos que no aceptan la construcción sí podemos ver realizaciones, como regresar. La explicación que se propone en (De Miguel, 1992: 78) para estos casos es que los verbos que no forman la CPA tienen un componente alto do actividad, a pesar de poder referirse al estado resultativo.

Un factor muy relevante a la hora de tratar cl aspecto de las CPA es que en este tipo de construeciones las características intrínsecas aspectuales de los verbos se ven con mucha claridad, puesto que, siendo la CPA una cláusula mínima, no hay factores oracionales que puedan influir en ella, excepto los adverbios apenas, después de, luego de, recién, una vez, que refuerzan su valor de anterioridad.

En lo que sigue propondremos un análisis de las restricciones en cuestión basado en la estructura interna de los eventos y la repercusión del clítico culminativo se en la misma. Nuestro plantcamiento, sin ser alternativo al que acabamos de reseñar (en cuanto relacionado con las características aspectuales del predicado), permite proporcionar una explicación más clara y exacta de las restricciones que aquí se están tratando.

A continuación reproduzco los tipos de eventos en función de su estructura interna de fases según De Miguel y Fernández Lagunilla (2000), clasificación basada en la representación geométrica de eventos de Pustejovsky $(1991)^{21}$.

17 En contra de lo expuesto en De Miguel (1992), volver sí puede participar en las CPA (véase también el ejempio de (13a)):

i. Recien vuelto González de la Argentina de Contázar y Borges, [...] le expuso a Julia la teoria del perro [...]. (Google)

I8 Como en seguida se podrá comprobar, las construcciones con 'acabado de' tienen las mismas restriccioncs que las CPA.

19 El porquć dc la perfectividad de la CPA recibe en De Miguel (1992) un tratamiento enmarcado en la Teoría de la Rección y el Ligamiento: un mecanismo de cotejo de rasgos permite que los verbos que denotan un cvento perfectivo puedan afijarse al morfema aspectual $d o$ especificado como [+pcrfectivo]; por el contrario, los verbos léxicamente imperfectivos no van a poder afijarse a do. En De Miguel (1999) se puntualiza que un evento ha de culminar en el punto final (seguido de un nuevo estado) para poder entrar en una CPA. Por esta razón los verbos ingresivos (que culminan en el punto inicial seguido de un proceso), como hervir cn su accpción inacusativa, resultan incompatibles con la CPA.

20 En el sentido inacusativo de este reloj atrasa.

21 Las representaciones formales del esquema 2 ham sido defendidas en varios estudios que tratan los fenómenos del español (los adverbios de foco aún, todavia, ya y el clítico culminativo se: Fernández Lagunilla y De Miguel, 1999; la formación de pasivas: De Miguel, 2003, etc.), del japonés (Tokunaga, 2001), del ruso (afijos de formación aspectual, direccionalidad de los verbos de movimiento: Batsiukova, 2004, etc.) y del italiano (Palmerini, 2002). 
a. Estado

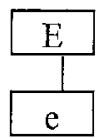

b. Proceso

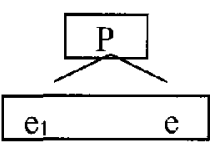

c. Transición (T1)

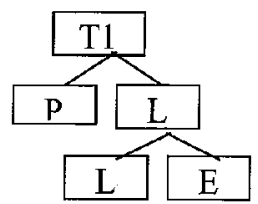

evento simple, con secuencia de eventos proceso o aclividad que desemboca en un duración y sin fases (tener, detestar) idénticos, con duración y fases: evento no delimitado (estudiar, nadar) punto seguido de un cambio de estado: evento delimitado con duración que culmina en la frase final (leer un libro, ver la pelicula)

\section{d. Logro simple (L1)}

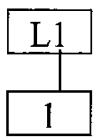

e. Logro compuesto (L2)

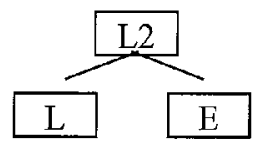

f. Logro compuesto (L3)

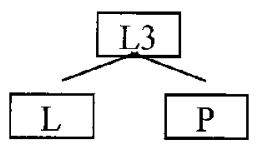

evento delimitado, que acurre en un punto (explotar, llegar, nacer) evento delimitado que culmina en un punto (la fase inicial) y va seguido de un estado (marearse, ocultarse, sentarse) evento delimitado que culmina en un punto (la fase inicial) y va seguido de un proceso (hervir, forecer, ver la costa) g. Transición (T2)

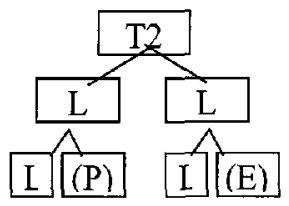

h. Proceso (P2)

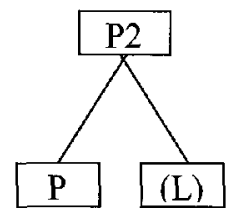

evento delimitado, que implica una transición entre dos puntos de culminación; tanto el subevento inicial como el final pueden a su vez descomponerse en dos fases (aparecer(se), bajar(se), caer(se), ir(se), morir(se), subir(se), venir(se), volver(se)) evento incrementativo o de acabamiento gradual

(adelgazar, 'engordar, encanecer; envejecer) 
Como se puede observar en el esquema 2, uno de los tipos eventivos, en concreto, la transición del tipo 2, abarca muchos verbos de desplazamiento: bajar(se), caer(se), ir(se), subir(se), venir(se), volver(se). Es más, todos estos verbos (excepto ir(se)) accptan la CPA:

(21) a. ¿Te gustaria saber lo que hace Xavi una vez bajado de la bici? (Google)

b. Una vez caido el Muro de Berlín la izquierda se ha acabado, parece que dicen, pero nada más lejos de la realidad. (Google)

c. Recién subido el actor al escenario, pasea entre cachivaches a medio desmontar $y$ desenfunda mientras sitúan los platos. (Google)

d. Condenado el niño a morir apenas venido al mundo, un guardador de rebaños le salvó y crió, amamantándole la perra que defendia el ganado. (Google)

Como en seguida se demostrará, esta coincidencia ( $\mathrm{T} 2$ y los verbos de movimiento inacusativos) no es ni mucho menos casual, y tiene que ver con la capacidad de determinados verbos de aceptar el clítico culminativo se (Fernández Lagunilla y De Miguel, 1999). Según las autoras, el clítico se es un operador aspectual que señala que el evento culmina en un punto que desemboca en un cambio de estado. Se culminativo es compatible, por tanto, con todos los tipos de eventos que contienen la fase $\mathrm{L}[\mathrm{L}+\mathrm{E}]$, que son $\mathrm{T} 1, \mathrm{~T} 2$ y L2.

El clítico culminativo puede aparecer tanto con los verbos inacusativos (22a) (el evento resultante sería T2) como con los transitivos cuyo objeto directo esté delimitado (22b) (el evento resultante sería $\mathrm{T} 1$ ):

(22) a. Juan se cayó al suelo.

b. Juan se leyó el libro de una sentada.

Volvamos ahora a los verbos de desplazamiento que no aceptan la CPA (recordemos que son acercarse, acudir, adelantarse, aproximarse, avanzar, moverse y regresar).

El verbo avanzar (de acabamiento gradual - P2), no puede participar en una CPA porque tiene el proceso como fase principal y carece de estado resultante (así, el resultado de engordar es 'estar gordo' y no 'estar engordado'). También son procesos graduales los verbos acercarse, adelantarse y aproximarse. Nótese que, acercarse, por ejemplo, no implica 'estar cerca' sino 'estar más ccrca'; por tanto, dichos verbos sólo son compatibles con la CPA pasiva ${ }^{22}$.

(23) a. Aproximada [acercada] la escalera a la pared, Alvaro Mesía se lanzó a la ocupación del aposento de Ana Ozores.

b. Una vez adelanlado el dinero para la investigación, la fundación se desentendió de sus becarios.

Acudir y regresar, que en principio pueden ser realizaciones, no visualizan su fase de logro final en la CPA y, en todo caso, carecen de estado resultante (al igual que entrar, que acepta la CPA con cierta dificultad; entrar y acudir no suponen necesariamente "estar den- 
tro'). En otras palabras, acudir y regresar son procesos seguidos de un logro $[\mathrm{P}+\mathrm{L}]^{23}$ y no pueden formar una CPA por no culminar en un cambio de estado.

(24) a. *Acudidos todos los invitados, empezó la fiesta.

b. *Regresado Miguel, nos fuimos al restaurante.

Los verbos irse y moverse poseen los dos el clítico se, que cumple la función de operador aspectual: delimita el evento y señala que éste posee una culminación seguida de cambio de estado [L+E]. Ahora bien, en una CPA que, como hemos dicho, no posec elementos oracionales que puedan favorecer la focalización de determinadas partes de la estructura eventiva de un verbo, la mencionada culminación $[\mathrm{L}+\mathrm{E}]$ puede quedarse sin manifestar; así, a falta de un SP o un tiempo verbal perfectivo que nos señale que el evento ha finalizado ('Juan se ha ido a Madrid', 'E] niño se movió') los verbos irse y moverse se interpretan como ingresivos. De hecho, De Miguel $(1999: 2986,2996)$ apunta que en el caso de los verbos inacusativos la presencia de se implica la existencia de un límite inicial. A diferencia de 10 que ocurre con irse y moverse, los verbos bajar(se), caer(se), subir(se), venir(se), volver(se) son (incluso sin se) eventos delimitados en su final, por esto ellos sí pueden participar en una CPA.

A su vez, dirigirse y encaminarse son inherentemente ingresivos; es decir, denotan el inicio del movimiento y carecen de una fase final (tiene la estructura eventiva de $\mathrm{L} 3[\mathrm{~L}+\mathrm{P}]$ ). Las CPA compuestas a partir de estos verbos siempre son pasivas:

(25) a. Encaminadas las negociaciones, cesaron los atentados terroristas.

b. Dirigido el misil hacia el objetivo, se descubrió que se trataba de un grupo de refugiados.

El test con la construcción terminativa 'acabado de' confirma el análisis presentado. Ninguno de los verbos que no aceptan la CPA puede seguir a 'acabado de'24.

En cuanto a las construcciones con estar al, que expresan la inminencia de un cvento, su uso es más restringido aún que el de las CPA y las construcciones con acabado de. Como se puede observar en los ejemplos de (12), que presentan todos los verbos que aparecen en CREA junto con estar al, esta construcción se usa exclusivamente con los verbos de dirección inherente caer, llegar, venir y volver (todos ellos compatíbles con la CPA y acabado de). La razón de esta restricción adicional se escapa al alcance del análisis presentado y se debe, tal vez, a que se trate de expresiones parcialmente lexicalizadas, fijas.

23 De hecho, regresar y acudir no aceptan el clitico culminativo se, señal de que no poseen la fase $[\mathrm{L}+\mathrm{L}]$ (compárese regresar con su sinónimo volver).

24 Se han podido encontrar algunos ejemplos con 'acabado de regresar":

i. "¿Cuáles son tus plunes ahora?»-le pregunté al amigo médico acabado de regresar del extranjero (Santo Domingo).

ii. [...] recuerdo la ultima vez que vi [...] a Cortázar aqui, [...] en diciembre de 1983, acabado dé regresar de las Naciones Unidas en Nueva York. (Santiago de Cali, Colombia).

Como se puede apreciar, estos ejemplos proceden del español latinoamericano y es muy probable que las caracteristicas eventivas de un verbo no se conceptualicen de la misma forma en el español peninsular y en su variante iberoamericana. 
Un último apunte que creo conveniente hacer está relacionado con los eventos de T2 y los verbos de movimiento. Según Cifuentes (1999: 60), el movimiento implica «un cambio de posición, $y$, por tanto, el haberse movido o el estar moviéndose significaría que una posición anterior ha sido dejada y una próxima posición está siendo tomada, o que se ha llegado a una próxima situación o que se está en el camino de ella». Esta visión del movimiento como una relación dinámica entre dos posiciones, una de partida y otra de llegada, justifica el uso de T2 como una estruclura eventiva eventualmente capaz de reflejar cualquier tipo de movimiento, puesto que codifica «transición entre dos estados o dos locaciones; es un evento compuesto de dos fases, ambas delimitadas, que tienen la posibilidad de mostrarse en su camino o trayectoria hacia el nuevo estado o locación, en el punto en que alcanzan la nueva locación o estado o incluso en una fase resultante posterior a ese punto" (De Miguel, 2003). Así, T2 permite describir con un único esquema el evento de ir(se), por ejemplo. La frase (26a) describiría el logro inicial [L], el punto de partida, se combina con un adverbial puntual. El ejemplo (26b) sería la parte [P], un proceso durativo. En (26c) se combinan la parte del proceso [P] y el logro [L] final, por eso es compatible con un adverbial delimitador. Por último, en la oración (26d) se ve reflejado el estado [E] posterior a la culminación, que, como era de esperar, admite el adverbial durativo.

(26) a. Juan se fue de Madrid a las tres.

b. En estos momentos Juan va a Barcelona.

c. Fue hasta Barcelona en dos horas.

d. Juan se fue a Barcelona durante dos meses.

En el presente apartado se ha demostrado que, al considerar las propiedades aspectuales como posible diagnóstico de la inacusatividad, se han de tener en cuenta múltiples rasgos de cada verbo, relacionados con su significado léxico, su estructura eventiva y los procedimientos mediante los que se formó dicho verbo (la afijación con se que en muchos casos implica delimitación). No basta con demostrar la telicidad del verbo: algunos de los verbos que se han estudiado aquí son inacusativos y potencialmente télicos $\mathrm{y}$, sin embargo, no pueden participar en la CPA y en la construcción terminativa con acabado de: acudir, regresar, etc., porque no visualizan su punto final, sino la trayectoria. En otras palabras, los verbos inacusativos también han de tener la fase de culminación (que, como se ha podido comprobar, no siempre coincide con la fase final) y estado resultante para que las pruebas aspectuales que aquí se han tratado se puedan aplicar a ellos.

\section{LA INTRANSITIVIDAD DE LOS VERBOS DE MOVMIENTO EN RUSO EN FUNCION DE SU NATURALEZA} SEMÁNTICA

Antes de abordar la tarea de presentar una clasificación de los verbos de movimiento en ruso en función de sus rasgos semánticos, revisaremos brevemente las pruebas de inacusatividad existentes en esta lengua. 


\subsection{Las pruebas de inacusatividad en ruso}

Como con razón apunta Pesetsky en su tesis «Paths and Categories» (1982), el primer estudio que trata el fenómeno de inacusatividad en ruso, esta lengua no posee indicios gramáticos claros que permitan distinguir entre los dos tipos de verbos intransitivos, a diferencia del italiano, por ejemplo. $Y$ dado que dicha distinción no está gramaticalizada (al igual que en español), hemos de buscar sus raíces en la semántica léxica. Como suele pasar en los casos en que los juicios de los hablantes dependen de factores semánticos, la distinción en ruso, «entre los verbos inacusativos y los inergativos [...] es difusa y depende del contexto y de la percepción por parte del hablante del grado de agentividad de la acción denotada por el verbo ${ }^{25}$ " (Pesetsky, 1982:59).

Pesetsky (1982) destaca una serie de fenómenos que indican de forma indirecta si el sujeto superficial de un verbo intransitivo ha sido derivado de un objeto en la estructura profunda. Estos fenómenos son: oraciones con genitivo negativo, construcciones distributivas con po y construcciones con numerales no concordadas ${ }^{26}$.

\subsubsection{La prueba de genitivo negativo ${ }^{27}$}

En ruso, ciertas expresiones nominales en oraciones con negación oracional (o existencial) pueden aparecer en caso genitivo opcionalmente. Estas expresiones nominales corresponden al objeto en caso acusativo (27a,a'), sujeto nominativo en una construcción pasiva $\left(27 \mathrm{~b}, \mathrm{~b}^{\prime}\right)$ y sujeto no agentivo de un verbo monádico (inacusativo) $\left(27 \mathrm{c}, \mathrm{c}^{\prime}\right)$ :

(27) a. Ja ne prines zvety.
Yo no he traído flores-ac.
'No he traido las flores'
a'. Ja ne prines zvetov.
Yo no he traído flores-gen.
'No he traido flores'
b. Ni odin kust
Ni un arbusto-nom. no ser regado-masc.sg.
'No ha sido regado ni uno solo de estos arbustos'
'Ni odnogo kusta ne bylo polito.
Ni un arbusto-gen. no ser regado-neutr.sg.
'No ha sido regado ni un solo arbusto'
c. Aqui no res ne recen-pl. rastut flores-nom.
'Aqui no crecen flores' (un determinado tipo de flores)

25 La parte final de la cita, que hace referencia a la agentividad de un verbo intransitivo, va a tener una importancia excepcional para esta parte del estudio.

26 Pesetsky (1982) interpreta los tres tipos de construcciones como instancias del sintagma cuantificaciona! SQ.

27 Entre los trabajos que califican la prueba del genitivo ncgativo como cl test más fiablc de la inacusatividad en ruso se puede citar asimismo a Neidle (1988) y Franks (1995). 


$$
\begin{array}{lll}
\text { c. Zdes' ne rastet } & \text { zvetov } \\
& 28 \\
\text { Aqui no } & \text { crecer-neutr.sg. } & \text { flores-gen. } \\
\text { 'Aqui no crecen flores' } &
\end{array}
$$

Nótese que la alternancia con genitivo negativo es imposible para los sujetos de los verbos tranșitivos (28a,b), hecho que apoyaría la validez de dicha prueba para el diagnóstico inacusativo:
a. Studenty
Estudiantes-nom tho
no
čitajut roman.
b. *Studentov ne
Estudiantes-gen. no
'Los estudiantes no leen la novela'
leen-pl. la novela.
citaet roman.
lecr-neutr.sg. la novela.

Una de las posibles causas de la existencia de dicha alternancia de casos es la falta de artículos en ruso, de manera que en determinados contextos el contraste entre la definitud y la no definitud se expresa a través de la elección del caso acusativo o nominativo por un lado, y del genitivo, por el otro, en oraciones negativas. Compárese las oraciones traducidas al castellano para poder apreciar esta diferencia: el genitivo negativo siempre motiva una lectura no-referencial ${ }^{29}$. De ahí el requisito que tiene que satisfacer el SN para poder usarse en la forma de genitivo negativo: no puede ser referencial, sino indefinido e inespecífico. La mayoría de los estudio relacionan esta restricción con la negación cxistencial (véase Franks, 1995; Partee y Borschev, 2002; Pereltsvaig, 1998, etc.). Efectivamente, en las oraciones con negación existencial se niega la existencia (valga la redundancia) de un evento y el SN con ćl asociado, y no se puede negar la existencia de un SN definido.

\subsubsection{Construcciones distributivas con po}

Una de las funciones de la preposición po en ruso es expresar la cuantificación distributiva, que no se manifiesta explícitamente en otras lenguas, como el español o el inglés. Las construcciones distributivas con po, al igual que los SN genitivos en oraciones negativas, pueden ser objetos de verbos transitivos (29a) y sujetos de oraciones pasivas (29b) y de verbos inacusativos $(29 \mathrm{c})$ (cn cste caso el orden de palabras no marcado será tambićn $V$ $\mathrm{SN}$ ), y, en cambio, resultan inaceptables como sujetos de los verbos transitivos e inergativos $(29 \mathrm{~d})$ :

28 Otro argumento a favor de la inacusatividad de este tipo de oraciones es el orden palabras: V-SN, que refleja que la posición del SN en la estructura profunda es la de objeto.

29 Es más que notable la similitud del tesi del genitivo negativo con uno de los diagnósticos de inacusatividad en español, a saber, el SN pospuesto sin determinante. Compárese:

i. No llegaron estudiantes.

ii. $\mathrm{Ne}$ prišlo studentov.

No llegar-neutr, estudiantes-gen. 
(29)

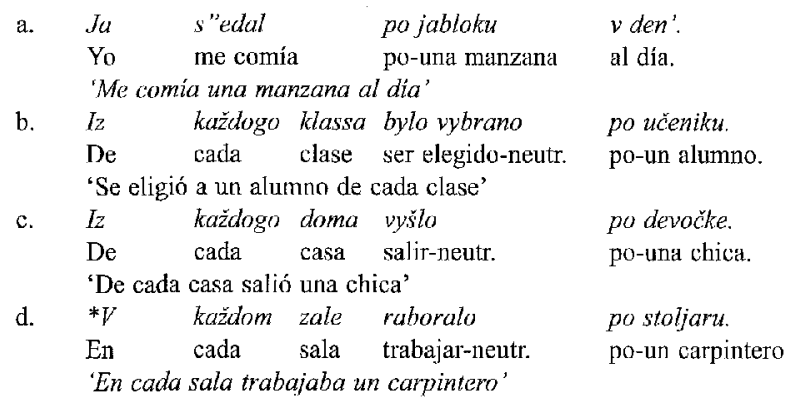

Al igual que en el ejemplo inacusativo (27c), el verbo de $(29 \mathrm{c})$ no concuerda con el sujeto superficial en género y número, como suele ser en el pasado, sino que está en su forma impersonal, de género neutro.

Sin embargo, esta prueba, que se da por válida cn numcrosos estudios que siguen a Pesetsky (1982) - Testelets (2001), Harves (2003a), etc.- presenta, según se demuestra en Harves (2003b), serios inconvenientes relacionados tanto con su sintaxis como con sus peculiaridades semánticas. Así, por ejemplo, la construcción distributiva con po puede aparecer en calidad de sujeto de algunos predicados transitivos (30a) e inergativos (30b); al mismo tiempo es rcchazada por ciertos verbos claramente inacusativos, según la autora, como bojat 'sja 'temer, asustarse' y bespokoit sja 'preocuparse' $(30 \mathrm{c})^{30}$.

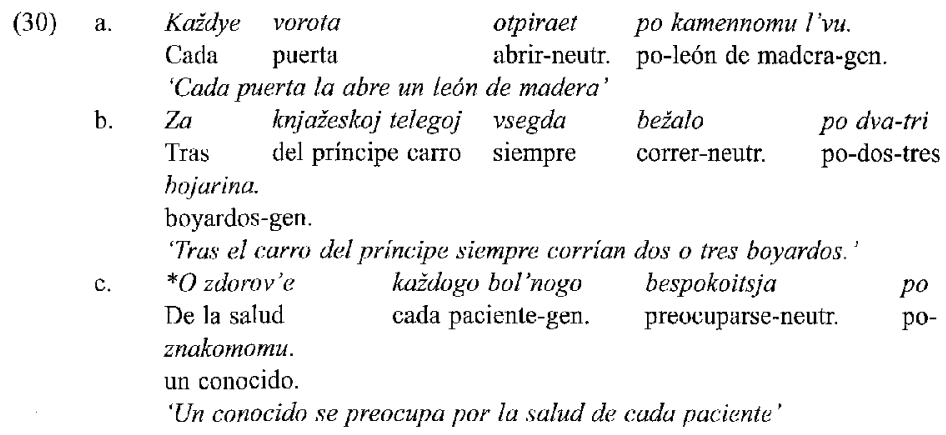

Además, como se ha mencionado supra, la construcción distributiva cuenta con varias restricciones de índole semántica. Una de ellas es que no puede haber una relación preexistente entre los dos SN: la llave distributiva (distributive key), cada chico en (31), y dominio distribuido (distributed share), una madre / una hermana en (31); si csta condición que no se cumple, cosa que ocurre a menudo, el ejemplo es inaceptable. Asi, aunque el verbo traer debería ser compatible con la construcción distributiva por ser transitivo, (31) es agramatical:

30 Jos ejemplos están tomados de Harves (2003b). 
(31)

$\begin{array}{llll}\text { *Každyj } & \text { malčik } & \text { privel } & \text { po materi / po sestre. } \\ \text { Cada } & \text { chico } & \text { trajo } & \text { po- una madre / una hermana. } \\ \text { 'Cada chico trajo a su madre / su hermana. }\end{array}$

En vista de las pruebas aportadas en Harves (2003b) creemos conveniente renunciar al uso del test de construcciones distributivas con po para que los resultados del presente estudio no se vean oscurecidos en exceso por las restricciones contextuales y semánticas de cada una de las pruebas.

\subsubsection{Construcciones con mumerales no concordadas}

Es otra de las pruebas señaladas por Pesetsky (1982) como aceptable únicamente para los SN internos al SV. Resulta que en ruso las construcciones con numerales, cuando expresan el sujeto, pueden concordar con el verbo (32a) o no (32b):

$\begin{array}{lll}\text { a. } & \text { Tri rebenka prišli. } & \\ & \text { Tres niños venir-pl. } & \\ & \text { 'Vinieron tres niños' } & \\ \text { b. } & \text { Prišlo tri } & \text { rebenka. } \\ & \text { Venir-neutr. tres niños. } \\ & \text { 'Vinieron tres niños' } & \end{array}$

Estas construcciones comparten con los $\mathrm{SN}$ genitivos en oraciones negativas ciertos rasgos que, como hemos indicado, relacionan el sujeto superficial con el objeto en la estructura profunda: la posición del SN no marcada es la posverbal en el caso del sujeto no concordado (32b); construcciones no concordadas pueden usarse, junto con las concordadas, para denotar el sujeto de un verbo inacusativo (32b) y de un verbo en voz pasiva (33a), pero el sujeto de un verbo transitivo (33b) o inergativo (33c) tiene que ser concordado ${ }^{31}$.

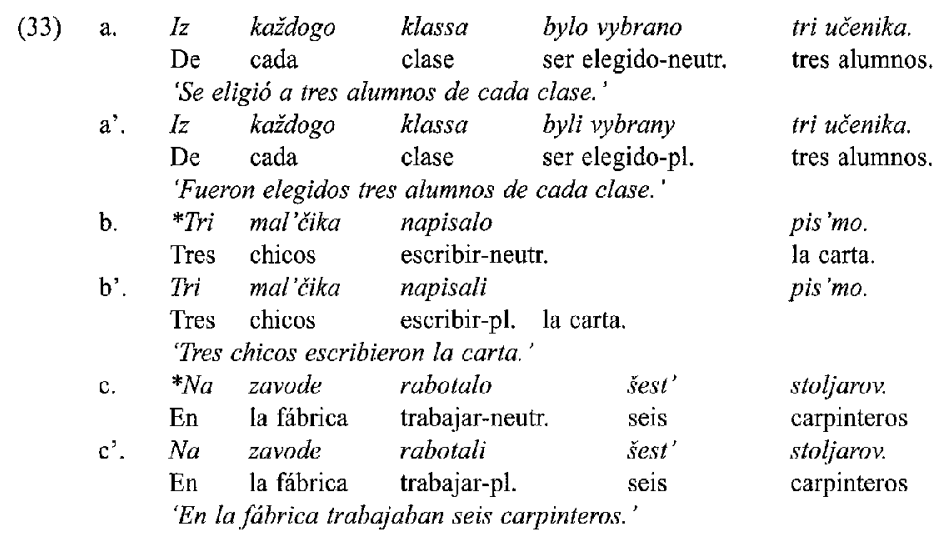

31 No podetnos hablar en este caso del objeto de los verbos transitivos, porque en ruso la concordancia sólo es de sujeto. 
Pesetsky reconoce que esta prueba no es tan concluyente como la del genitivo negativo, sobre todo por la alternancia de construcciones concordadas con las no concordadas incluso para los verbos claramente inacusativos. Proponemos, pues, el uso de una serie de diagnósticos adicionales, que permiten determinar si el $\mathrm{SN}$ de un verbo intransitivo es su sujeto o no (Franks, 1995:66).

a) Un sujeto puede ser antecedente de pronombres reflexivos.

b) Un sujeto puede controlar cláusulas con gerundio y otros tipos de adjuntos adverbiales.

Lógicamente, los verbos inacusativos fallan este diagnóstico pucsto que su sujeto superficial se deriva del objeto:

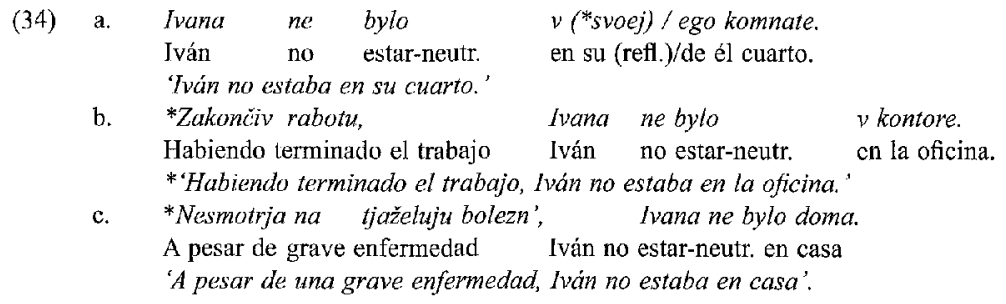

\subsection{Clasificación de los verbos de movimiento en ruso}

En lo que sigue presentamos un análisis detallado de los distintos grupos de los verbos de movimiento en ruso. Para facilitar la comparación de los datos de las dos lenguas (el español y el ruso) hemos seleccionado verbos equivalentes semánticamente a los que han sido tratados en el $\$ 4$.

5.2.1. Verbos de dirección inherente ${ }^{32}$ : vysumul'sja ${ }^{P}$ - vysovyvat'sjal 'asomarse', napravit'sja ${ }^{P}$ - napravljat'sja 'dirigirse', otdalit'sja" - otdaljat'sja 'alejarse', povysit'sja ${ }^{P}$ - povyšat'sja 'ascender, elevarse', spustit'sja ${ }^{P}$ - spuskat 'sja 'bajar, descender'

Como se ha puesto en evidencia en el apartado 4.1., los verbos de dirección inherente pueden focalizar la fase del trayecto y la del destino del movimiento. Pues bien, en ruso la forma imperfectiva es la que se encarga de visualizar el trayecto (35a), y la perfectiva, cl destino (35b):

$$
\begin{array}{lll}
\text { a. On } & \text { spuskalsja } & v \text { dolinu. } \\
\text { Él bajar-pas.imperf. } & \text { al valle } \\
\text { 'El estaba bajando al valle.' } & \\
\text { b. On } & \text { spustilsja } & v \text { dolinu. } \\
& \text { Él bajar-pas.perf. } & \text { al valle. } \\
& \text { 'El bajó al valle.' }
\end{array}
$$

32 Como en ruso la mayoría de los verbos tiene dos formas, perfectiva c imperfectiva, incluimos las dos en la lista. En seguida explicaremos de qué manera influye la diferencia de aspecto gramatical en la semántica de ambos verbos de cada pareja. 
Estos verbos de dirección inherente se forman a partir de los respectivos verbos causativos mediante la sufijación con -sja ( $-s^{\prime}$ después de vocales), un proceso de intransitivización muy productivo en ruso, al igual que algunos de sus equivalentes en castellano: alejar - alejarse, asomar - asomarse, etc. Al ser eventos derivados de formas causativas y tener focalizado el subevento resultante, estos verbos, en principio, deberían mostrar comportamiento inacusativo. Efectivamente, aceptan SN genitivo cn oraciones negativas:

$$
\begin{array}{llll}
\text { Ne vysumulos' } & \text { ni } & \text { odnogo } & \text { čeloveka. } \\
\text { No asomarse-neutr. ni } & \text { una } & \text { persona-gen. } \\
\text { 'No se asomó ni una sola persona.' } & &
\end{array}
$$

No obstante, los mismos verbos también pueden interpretarse como inergativos. Una prueba de que la variante concordada de (37) es inergativa es que el verbo concordado acepta adjunto con gcrundio, a diferencia del no concordado; el SN es, por tanto, un sujeto verdadero:

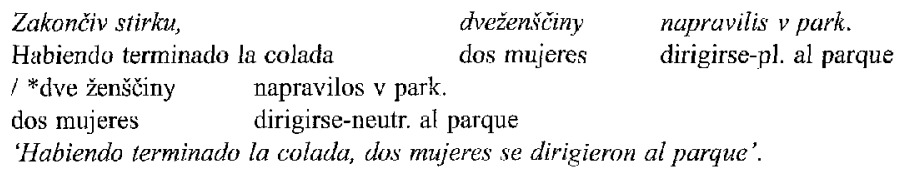

Con los sujetos inanimados, en cambio, sólo es posible la lectura inacusativa: el orden no marcado cn (38a) es V-SN, con un verbo no concordado; además, en este caso el sustantivo no puede ser antecedente de un pronombre reflexivo (38b):

\begin{tabular}{|c|c|c|c|c|}
\hline a. & $\begin{array}{l}\text { Spustilos' } \\
\text { Bajar-neutr. } \\
\text { 'Bajaron uno }\end{array}$ & $\begin{array}{l}\text { neskol' } \\
\text { unos gl } \\
\text { globos' }\end{array}$ & $\begin{array}{l}\text { šarov. } \\
\text { s. }\end{array}$ & \\
\hline b. & Neskol'to & sarov & spustilos' & $k$ (*svoej) baze. \\
\hline & Unos & globos & bajar-neutr. & a su base \\
\hline
\end{tabular}

Resumiendo, podemos constatar que cl comportamiento sintáctico de los verbos de dirección inherente en ruso y español es similar cuando el sujeto superficial es inanimado: dichos verbos en las dos lenguas se muestran como claramente inacusativos. Sin embargo, cuando el participante es animado, un hablante del ruso tiene la opción de interpretar el verbo como inergativo o inacusativo. Recuérdese la cita de Pesetsky (1982), en la que se apunta que la distinción entre los dos tipos de verbos intransitivos en ruso depende de la percepción por parte del hablante del grado de agcntividad de la acción. En otras palabras, si el hablante interpreta al participante del evento como agente (causante del evento), el verbo se comportará como inergativo, y si lo equipara al tema (o experimentante), surgirá el efecto inacusativo.

En esta relación son muy interesantes los resultados de la investigación de Babyonishev et al. (2001) sobre el uso de construcciones inacusativas en el lenguaje infantil. Los autores demuestran que los niños rusos, hasta alcanzar cierta edad ( 4 o 5 años) interpretan todas las construcciones inacusativas (incluso con los verbos más claramente inacusativos - los de 
existencia y aparición) como inergativas, asignándole al SN en oraciones negativas el caso nominativo (el caso del sujeto por excelencia) cn vez del genitivo, obligatorio para el SN de los verbos inacusativos en condiciones de negación existencial (Babyonishev et al., 2001:39):

Vetom dome bylo okno, a v tom dome ne bylo
Fn esta casa había ventana y en aquella casa no había
$\begin{aligned} & \text { okno-nom. } \\ & \text { okna-gen. NIÑO }\end{aligned}$
'En esta casa habia una ventana, y en aquella no habia ninguna ventana'.

La explicación que se propone en el trabajo citado es la siguiente: los niños pequeños no relacionan la posición de sujeto en la estructura superficial con la de objeto en la estructura profunda porque no pueden formar cadenas argumentales, gracias a las que se llena y recibe papel temático la posición de argumento externo de un verbo inacusativo.

5.2.2. Verbos de dirección derivados de los de manera de moverse mediante prefijos perfectivizantes ${ }^{33}$

Estc grupo corresponde a los verbos de manera de moverse en español con un adjunto (SP) de destino. La diferencia es que el ruso puede fusionar en la misma forma verbal los elementos semánticos de desplazamiento y manera (igual que el chino y todas las lenguas indoeuropeas excepto las romances) con $\mathrm{cl}$ de trayectoria mediante un prefijo perfectivizante $^{34}$, mientras que el español sólo puede lexicalizar los conceptos de desplazamiento y trayectoria, siendo el concepto de manera de moverse el reservado para los verbos de manera de moverse:

$$
\begin{array}{lll}
\text { a. Iván } & \text { p-bežal } \\
\text { Iván } & \text { en-corrió (desplazamicnto + mancra + trayectoria) } \\
\text { b. Iván } & \text { entró } & \text { corriendo } \\
\text { despl-to + trayect. } & \text { manera }
\end{array}
$$

$\checkmark$ magazin.

en la tienda

en la tienda.

Como se demuestra en Batsiukova (2004), las distintas formas derivadas del mismo verbo de movimiento son sus Aktionsarten o, hablando cn términos de las estructura eventiva, las distintas partes focalizadas de T2 (esquema 2, g). Pongamos por ejemplo las formas prefijadas de plyt' 'nadar':
a. u-plyt' 'irse nadando',
Aktionsart ingresiva, abandono de la posición inicial
b. pri-plyt' 'venir nadando'
Aktionsart terminativa, el objeto alcanza
c. pro-plyt' 'nadar cierta distancia' la ubicación final y un nuevo estado Aktionsart perdurativa, movimiento a lo largo de un período de tiempo

\footnotetext{
33 Según los resultados del estudio de Nichols (1993), los verbos de movimiento son los que más lormas perlectivas tienen. Probablemente este hecho tenga que ver con la variedad de formas prefijadas perfectivas existentes que, como se demostrará a continuación, representan distintos matices de índole aspectual.

34 Muchos de los prefjos verbales rusos se han formado históricamente a partir de adverbios y preposiciones de espacio y tiempo, de ahí que sean capaces de codificar la trayectoria: $v$ 'en', $z a$ 'detrás', pri 'al lado de', etc.
} 
Los verbos de este grupo, al igual que los del primero, pueden mostrar comportamiento inergativo o inacusativo si el sustantivo es animado, dependiendo de la interpretación del hablante.

$\begin{array}{llll}\text { (42) a. Pjat' krasivyx devušek prišli. (Franks, 1995: 106) } \\ \text { cinco guapas chicas venir-pl. } \\ \text { b. Prišlo } \quad \text { pjat' krasivyx } & \text { devišsek. } \\ & \text { venir-neutr. chinco guapas } & \text { chicas. } \\ & \text { 'Vinieron cinco chicas guapas' } & \\ \text { c. Ne prišlo } & n i & \text { odnoj krasivoj devuški. } \\ & \text { No venir-neutr. ni } & \text { una chica guapa-gen. } \\ & \text { 'No vino ni una sola chica guapa' }\end{array}$

La compatibilidad del verbo 'venir' con el genitivo negativo demuestra en principio que éste es inacusativo. Nótese, sin embargo, que tanto la estructura inergativa como la inacusativa es posible: en (42a) el orden de palabras es SN-V, propio de las frases transitivas e inergativas y el predicado concuerda con el sujeto en número (pl.) y persona ( $3^{a}$ ); en (42b) el orden de palabras es el propio de las frases inacusativas (V-SN) y el predicado no concuerda con el sujeto, manifiesta el género neutro.

Uno de los diagnósticos de sujeto, el de la compatibilidad con las cláusulas de gerundio, falla con la variante no concordada (inacusativa) (43a), aunque en principio son posibles las dos interpretaciones (43b) (Franks: 121):
a. Vozvraščajas' domoj,
Volviendo a casa
pjat' mal'čikov

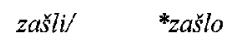
$\checkmark$ magazin.
cinco chicos
entrar-pl./entrar-neutr
en una tienda
'Al volver a casa, cinco chicos cntraron en una tienda'
Por cl camino casa cinco chicos entrar-pl./entrar-neutr
$v$ magazin.
on una tionda
'Camino de casa cinco chicos entraron en una tienda'
b. Po doroge domoj, pjat'mal'čikov zašlil zašlo

Con sujetos inanimados, en cambio, sólo es posible la lectura inacusativa: la variante concordada es agramatical y el orden de palabras no marcado es V-SN (44a); si lo alteramos (44b), la implicación de la oración sería 'y el resto no llegó', es decir, el SN se interpreta con una lectura de contraste: está focalizado y por eso ocupa esa posición a la izquierda del verbo:

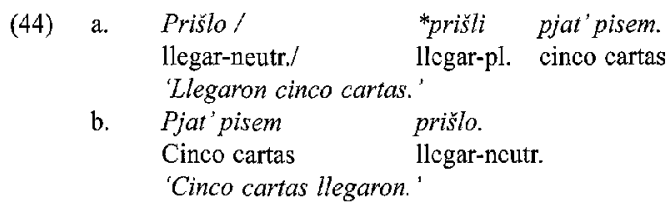


El comportamiento variable de construcciones intransitivas con un sujeto animado (propio de los verbos de los grupos 1 y 2) es un tema ampliamente debatido (Levin y Rappaport Hovav, 1995; Partee y Borschev, 2002; Franks, 1995, entre otros). En los trabajos citados se señala que en muchas ocasiones, para que se pueda conseguir el cfecto inacusativo, un verbo que no es inherentemente inacusativo tiene que «acomodarse» al contexto inacusativo, sacrificando o modificando una parte de su contenido semántico, «desagentivizándose», volviéndose más existencial (asemejándose en gran parte a ser o estar). Si la lcctura existencial sc bloquea (por el uso de un SN referencial, por ejemplo), la interpretación inacusativa de la oración es imposible, como ilustra el contrastc entre (45b), que es inaceptable, y (45a), que resulta aceptable pero es inergativo:
a. Eti pjat'
krasivyx devušek
estas cinco-nom.
guapas chicas
b. *Etix pjati
krasivyx devušek
estas cinco-gen.
guapas chicas
'Vinieron estas cinco chicas guapas.'
prišli. (Franks, 1995: 100)
venir-pl.
prišlo.
venir-neutr.

\subsubsection{Verbos de manera de moverse}

Son siempre atélicos en ruso, porque no son prefijados, son imperfectivos.

Pueden tener asociado el rasgo 'manera de moverse' al rol agentivo (como el grupo 2 del cspañol): guljat' 'pasear', taščit sja 'arrastrarse', šagat' 'marchar' o relacionarlo con el rol formal (como el grupo 3 del español) o el agentivo dependiendo de si el sustantivo es animado o no: idti 'ir', bežat' 'correr', plyt' 'nadar o flotar', letet' 'volar', skolzit' 'deslizarse'.

Como en el caso de los verbos de movimiento en español, la distribución del rasgo 'manera de moverse' resulta decisiva para la configuración sintáctica del verbo. Asi, los verbos que asocian la manera de moverse al rol agentivo (los de causa interna) siempre son inergativos: su sujeto es claramente un agente y no pueden estar delimitados (ya que no son prefijados como los verbos del segundo grupo), son típicos procesos agentivos atćlicos. Su carácter inergativo se demuestra por el orden de palabras SN-V (46a), por el hecho de que el SN puede ser antecedente de un pronombre reflexivo (46b) y, por último, por su incompatibilidad con el genitivo negativo $(46 \mathrm{c})^{35}$ :

35 Aunque Fransks (1995) resta fuerza a esta prueba, en la medida en que en la lengua coloquial tambićn los verbos inergativos (i) y los transitivos (ii) coaparecen con genitivos negativos:
(i)
Nad
etoy
zadač
ne rabotalo
'Ni un solo estudiante trabajó sobre esia tarea'
(ii) Etu lonigu
$\begin{array}{ll}\text { Etu linigu } & \text { ne čitalo } \\ \text { Este libro-ac. no leer-neutr. } & \text { ni un estudiante-gen. }\end{array}$
'Ni un solo esiudiante se leyó este libro' dada (inacusativa) de manera muy ocasional, eso sí:
(iii) Zenšcin
guljalo
uže
kak obycno. (CNLR)
Mujeres-gen. pasear-neutr. ya como de costumbre.
'Ya paseaban tantas mujeres como de costumbre'

ni odnogo studenta.

ni un estudiante-gen.

ni odnogo studenta.

También los verbos de mancra de moverse, en principio inergativos, pueden usarse en la forma no concor- 
(46)
a. Soldaty šagajut družno.
Los soldados marchar-pl. todos juntos.
'Los soldados marchan todos juntos.'
b. Barin guljaet posvoemu pomest'ju.
El señor pasear-3a pers.sg. por su (reflex.) finca.
'El señor pasea por su finca.'
c. *Nikakix soldat ne šagalo
Ningún soldados-gen. no marchar-neutr. por la calle
'Ninguin soldado marchaba por la calle.'

Por cl contrario, los verbos que pueden asociar la manera de moverse tanto al rol agentivo (si el sustantivo es animado) como al rol formal muestran un comportamicnto variable: son inergativos en el primer caso e inacusativos en el segundo. Fijémonos, por ejemplo, en cl verbo plyt', que significa 'nadar' si va acompañado de un sustantivo animado y 'flotar" si el sustantivo es inanimado. La oración (47a) es inacusativa porque responde positivamente al test del genitivo negativo; en cambio, (47b), también negativa, sólo es aceptable si plyt' es 'flotar' y si 'estudiantes' se interpreta como 'cuerpos de estudiantes' (sustantivo inanimado):
a. Nikakogo mjasa
Ninguna carne-gen.
ne plavalo v supe.
'No había carne flotando en la sopa.'
b. Nikakix studentov ne plavalo $\quad$ reke.
Ningunos estudiantes-gen. no flotar-neutr. en el río
'No había estudiantes flotando en el rio'
b'. *Nikakix studentov ne plavalo $v$ reke.
Ningunos estudiantes-gen. no nadar-neutr. en el rio
'No habia estudiantes nadando en el rio'

Antes de pasar a exponer los resultados generales del presente estudio recapitulemos en forma de tablas el comportamiento de los distintos grupos de los verbos de movimiento en ruso (48a) y en español (48b) para poder compararlos.

(48) a. Ruso

\begin{tabular}{|c|c|c|}
\hline Dirección inherente & $\begin{array}{c}\text { Manera + dirección } \\
(V \text { de manera }+ \text { prefijo })\end{array}$ & Manera \\
\hline $\begin{array}{l}\text { animado: inergativo } \\
\text { inacusativo } \\
\text { inanimado: inacusativo }\end{array}$ & $\begin{array}{l}\text { animado: inergativo } 0 \\
\text { inacusativo } \\
\text { inanimado: inacusativo }\end{array}$ & $\begin{array}{l}\text { animado: inergativo } \\
\text { inanimado: inacusativo }\end{array}$ \\
\hline
\end{tabular}

b. Español

\begin{tabular}{|c|c|c|}
\hline Dirección inherente & $\begin{array}{l}\text { Manera + dirección } \\
(V \text { de manera }+S P)\end{array}$ & Manera \\
\hline $\begin{array}{l}\text { animado: inacusativo } \\
\text { inanimado: inacusativo }\end{array}$ & $\begin{array}{l}\text { animado: inacusativo } \\
\text { inanimado: inacusativo }\end{array}$ & $\begin{array}{l}\text { animado: inergativo } \\
\text { inanimado: inacusativo }\end{array}$ \\
\hline
\end{tabular}


Concluimos, pues, que en las dos lenguas los factores decisivos que determinan la configuración semántica son la delimitación (o la telicidad), tal y como ha sido interpretada aquí, y la animacidad del sustantivo que forma parte de la construcción. La telicidad (o focalización léxica) es el rasgo que predetermina el comportamiento de los verbos de dirección inherente en español (todos ellos son inacusativos) y en gran parte el de los respectivos verbos rusos. Por otra parte, la distribución del rasgo de manera de moverse ${ }^{36}$, que, como se ha demostrado, depende de si el SN es animado o no, influye, junto con la delimitación, en las características sintácticas de los verbos de manera de moverse; de hecho, los verbos de manera de moversc no delimitados se comportan sintácticamente de la misma forma en las dos lenguas. La diferencia básica estriba en que mientras en español el rasgo de la delimitación prevalece sobre el de animacidad (por esto los verbos animados de las primera y la segunda columna son inacusativos), en ruso el hablante tiene la opción de reflejar los respectivos eventos como más o menos agentivos, haciendo que el SN animado se interprete como agente o como tema.

\section{CoNCLUSIÓN}

Ahora sí podemos contestar a las preguntas que has sido planteadas en la introducción:

1. ¿Existe una relación directa entre determinados tipos eventivos y la inacusatividad?

No, no existe una relación directa entre los tipos eventivos de Vendler o cualquier otra clasificación fija de eventos por un lado y la inacusatividad por el otro, dado que hay otros factores semánticos que repercuten en el comportamiento sintáctico de un verbo. Los verbos inacusativos (incluidos los de movimiento) pueden tener una estructura eventiva télica (ser logros o realizaciones) o atélica (scr procesos o estados).

2. ¿Cómo de fiables son las pruebas de la inacusatividad de índole aspectual (las CPA, construcciones con recién, estar al, acabado de en español) y qué restricciones tienen?

Las pruebas de la inacusatividad de índole aspectual son fiables en cuanto ponen de manifiesto los rasgos eventivos de un verbo que pueden repercutir en su configuración sintáctica (la perfectividad o la capacidad de visualizar su fase final). Sin embargo, estos diagnósticos obviamente no pueden utilizarse en los casos en los que la telicidad y la inacusatividad son composicionales (verbo de manera de moverse más un SP o un prefijo, por ejemplo) o para verbos inacusativos atélicos (verbos no agentivos de manera de moverse).

Como se ha podido comprobar, las restricciones de este tipo de pruebas tienen que ver con la estructura eventiva del verbo (ha de contar con una fase de culminación seguida de estado resultantc).

3. ¿Cómo repercuten los rasgos semánticos del único argumento del verbo en su comportamiento sintáctico y cuáles de ellos son relevantes al respecto (la agentividad, el grado de afectación, la animacidad, etc.)?

A lo largo de las distintas secciones de este estudio sc ha demostrado la importancia que tienen los rasgos semánticos del SN sujeto para la configuración sintáctica de un SV cuyo núcleo es un verbo intransitivo. Se ha visto que un sustantivo inanimado (un SN no agentivo) siempre provoca una interpretación inacusativa del verbo y de la oración. En el caso de los verbos de manera de moverse, las características del objeto (codificadas en su 
rol formal) tienen que compaginarse de forma adecuada con una manera de moverse dada; si los rasgos del SN y del verbo no concuerdan el resultado será agramatical (*la piedra bota). Por otra parte, si el sustantivo es animado, sí es posible la lectura inergativa de un verbo de movimiento. Para que se de cl cfccto inergativo y el SN se interprete como agente, el requisito en español es que el verbo de movimiento no esté delimitado. En ruso, en cambio, la percepción por parte del hablante del grado de agentividad del SN animado no depende de la delimitación y cs la que determina en cada caso si el evento es inacusativo o inergativo.

4. ¿Qué mecanismo se encarga de relacionar los rasgos semánticos del verbo y las características sintácticamente relevantes del SN?

En el Lexicón Generativo (Pustejovsky, 1995) se postula la existencia del mecanismo llamado co-composición que se activa para cotejar determinados rasgos de los componentes del predicado y alterar sus propiedades inherentes algunas veces. Es por eso porque el rasgo 'manera de moverse' se conceptualiza de forma distinta (como caracteristica del evento en general o como manera individual del participante) si el verbo se combina con un sustantivo animado o uno inanimado. La co-composición es responsable también de que cuando los verbos de manera de mover se combinan con un SP se interpreten como dotados de dirección y, en definitiva, como delimitados.

5. ¿Constituye la inacusatividad una característica inherente de cada verbo o más bien se deriva composicionalmente?

Son muy pocas las ocasiones en las que podemos decir de entrada que un verbo (de movimiento en este caso) es inacusativo o no. En español sólo pasa con los verbos de dirección inherente (venir, entrar, etc.), y en ruso no es posible fuera del contcxto (ya que siempre depende de la animacidad del SN). El comportamiento sintáctico de un verbo depende de la información proporcionada por el resto de los constituyentes del predicado: en el caso de los verbos de comportamiento variable la prescncia o falta de un objeto determina la lectura transitiva o inacusativa de la oración, a través de la focalización del evento inicial o el resultante; también repercuten en la configuración sintáctica, como se ha mencionado supra, la presencia de un SP y determinados rasgos semánticos del SN. De ahí que el predicado se deba de estudiar como una unidad compleja, teniendo en cuenta todos sus constituyentes y las relaciones que entre ellos se establecen.

\section{REFERENCIAS BIBLIOGRÁFICAS}

Babyonishev, M., Ganger, J., Pesetsky, D., Wexler, K. (2001): «The Maturation of Grammatical Principles: Evidence from Russian Unaccusatives», Linguistic Inquiry, 32-1, MIT, págs. 1-44.

Batsiukova, V. (2003): «Operadores aspectuales en ruso: su estructura cventiva y su función en la representación formal de la oración», Revista Española de Lingüística, 2003, en prensa.

Batsiukova, V. (2004): «Direccionalidad de los verbos de movimiento. Un análisis subeventivo», comunicación presentada en el XIX Encucntro de la Asociación de Jóvenes Lingüistas (Valencia, 2004), a publicar próximamente en Interlingüistica, 15.

Belletti, A. y L. Rizzi (1987): «Los verbos psicológicos y la tcoría temática», en Demonte, V. y M. Fernández Lagunilla (eds.): Sintaxis de las lengzas románicas, Madrid, El arquero, págs. 60-122.

Burzio, L. (1981): Intransitive Verbs and Italian Auxiliaries, tesis doctoral, MIT.

Burzio, L. (1986): Italian Syntax. A Government-Binding Approach, Dordrecht, Kluwer.

Castillo Herrero, E. (2002): Inacusatividad y aspecto léxico en los verbos de movimiento. Estudio diacrónico, Girona, Scripta. Documenta Universitaria. 
Cifuentes Honnubia, J. L. (1999): Sintaxis y semóntica del movimiento, Alicante, Instituto de Cultura «Juan Gil-Albert».

CNLR: Nacional'nyj Korpus Russkogo Jazyka [Corpus Nacional de la Lengua Rusa], http://ruscorpora.ru.

CREA: Corpus de Referencia del Español Actual: http://corpus.rae.es/creanet.html.

Fernández Lagunilla, M. y F. Miguel, de (1999): «Relaciones entre el léxico y la sintaxis: adverbios de foco y delimitadores aspectuales», Verba 26, págs. 97-128.

Franks, S. (1995): Parameters of Slavic: Morphosyntax, Oxford University Press.

Gràcia i Solé, Ll. (1989): Els verbs ergatius en catalá, Menorca, Institut Menirquí d'Estudis.

Grimshaw, J. (1992): Argument Structure, Cambridge, MIT Press.

Hale, K. y S. J. Keyser (1986): «Some Transitivity Alternations in English», Lexicon Project Working Papers 7, Cambridge, Center for Cognitive Science.

Harves, S. (2003a): Unaccusative Syntax in Russian, MIT.

Harves, S. (2003b): «The distributive Construction with Preposition po as a diagnostic for unaccusativity in Russian», http://www.cla.sc.edu/ling/FASL13/abstracts/kuznctsova.

Kishimoto, H. (1996): «Split Intransitivity in Japanese and the Unaccusative Hypothesis», Language, 72-2, , págs. 248-286.

Levine, B. y M. Rappaport Hovav (1992): «The lexical semantics of verbs of motion: the perspective from unaccusativity», en I.M. Roca (ed.): Thematic Structure: Its Role in Grammar, Berlin, Mouton de Gruyter.

Levine, B. y M. Rappaport Hovav (1995): Unaccusativity at the Syntax-Lexical Semantics Interface, Cambridge, MIT Press.

Mendikoetxea, A. (1999): «Construcciones inacusativas y pasivas», en Bosque, I. y V. Demontc (eds.), Gramática descriptiva de la lengua española, Madrid, Espasa Calpe, págs. 1575-1629.

Miguel, E. de (1992): El aspecto en la sintaxis del español: perfectividad e impersonalidad, Madrid, Ediciones de la Universidad Autónoma de Madrid.

Miguel, E. de (1999): «El aspecto léxico», en Bosque, I. y V. Demonte: Gramáticu descriptiva de la lengua española, Espasa Calpe, págs. 2987-3060.

Migucl, E. de y M. Fernández Lagunilla (2000): «El operador aspectual SE», en Revista Española de Lingüistica, 30-1, 2000, págs. 13-43.

Migucl, E. de (2003): «El aspecto y sus relaciones con otras catcgorias gramaticales», ponencia presentada en el Ciclo Lingüístico de Braga, Universidad de Miño, manuscrito inédito.

Morimoto, Y. (2001): Los verbos de movimiento, Madrid, Visor Libros.

Neidle, C. (1988): The Role of Case in Russian Syntax, Kluwer Academic Publishers.

Nichols, J. (1993): «Transitive and causative in the Slavic lexicon: Evidence from Russian», en Comrie, B. y M. Polinsky (cds.): Causatives and Transitivity, John Benjamins.

Palmerini, M. (2002): «Un'analisi della semántica dei nomi deverbali in "-mento" e '-zione'», trabajo de doctorado, Università degli Studi «ROMA TRE».

Partee, B. y Borschev, V. (2002): «Existential Sentences, BE, and the Genitive of Ncgation in Russian), http://www-unix.oit.umass.edu/ partee/docs/Nancy4.pdf.

Pereltsvaig, A. (1998): «The genitive of Negation and Aspect in Russian», http://www.hum.uit.no/a/ pereltsvaig/geneg_and_aspect_mcgwpl.pdf.

Perlmutter, D. M. (1978): "Impersonal passives and the Unaccusative Hypothesis», Proceedings of the Fourth Annual Meeting if the Berkeley Linguistics Society, págs. 157-189.

Pesetsky, D. (1982): Paths and Categories, tesis doctoral inédita, MIT.

Pustejovsky, J. (1991): «The Syntax of Event Structure», cn Levine, B. y S. Pinker, (eds.), Lexical and Conceptual Structure, Oxford, Blackwell, págs. 47-81.

Pustcjovsky, J. y F. Busa (1995a): «Unaccusativity and Event Composition», en Bertinetto, P. M. (ed.): Temporal Reference, Aspect and Actionality, Torino, Rosenberg \& Sellier, págs.159-177.

Pustejovsky, J. (1995b): The Generative Lexicon, Cambridge, Massachusetts, MIT Press. 
Ramchand, G. (2002): «Aktionsart, L-syntax and Sclection», University of Oxford, manuscrito inédito.

Rosen, C. (1984): «The Interface between Scmantic Roles and Initial Grammatical Relations», en Perlmutter D. M. y C. Rosen (eds.): Studies in Relational Grammar 2, Chicago, Chicago University Press, págs. 38-77.

Sanz, M. (1996): Telicity, objects and predicate types. A cross-linguistic study of the role of syntax in processing, tesis doctoral, University of Arizona.

Tenny, C. (1987): Grammaticalizing aspect and affectedmess, Tesis doctoral, Cambridge, MIT.

Testelets, Ja. (2001): Vvedenie v obščij sintaksis [Introducción en la sintaxis general], Moscú, RGGU.

Tokunaga, S. (2001): Clases aspectuales de verbos y restricciones aspectuales de la formación pasiva en japonés, tesis doctoral inćdita, Universidad Autónoma de Madrid.

Van Valin, R. (1990): «Semantic Parameters of Split Intransitivity》, Language 13, págs. 91-116.

Van Voorst, J. (1986): Event Simucture, tesis doctoral, University of Ottawa, 1986.

Zaenen, A. (1993): «Unaccusativity in Dutch: integrating syntax and lexical scmantics», en Pustejovsky, J. (ed.): Semantics and the lexicom, Dordrecht, Kluwer, págs. 129-161. 